\title{
Concept development of a method for identifying friction coefficients for the numerical simulation of clinching processes
}

\author{
Max Böhnke $^{1} \cdot$ Moritz Rossel $^{1} \cdot$ Christian R. Bielak $^{1} \cdot$ Mathias Bobbert $^{1} \cdot$ Gerson Meschut $^{1}$
}

Received: 1 April 2021 / Accepted: 30 August 2021 / Published online: 19 September 2021

(C) The Author(s) 2021

\begin{abstract}
In order to reduce fuel consumption and thus pollutant emissions, the automotive industry is increasingly developing lightweight construction concepts that are accompanied by an increasing usage of aluminum materials. Due to poor weldability of aluminum in combination with other materials, mechanical joining methods such as clinching were developed and established in series production. In order to predict the relevant characteristics of clinched joints and to ensure the reliability of the process, it is simulated numerically during product development processes. In this regard, the predictive accuracy of the simulated process highly depends on the implemented friction model. In particular, the frictional behavior between the sheet metals as well as between the sheet metal and clinching tools has a significant impact on the geometrical formation of the clinched joint. No testing methods exist that can sufficiently investigate the frictional behavior in sheet materials, especially under high interface pressures, different relative velocities, and long friction paths, while allowing a decoupled consideration of the test parameters. This paper describes the development of further testing concepts based on a proven tribo-torsion test method for determining friction coefficients between sheet metal materials for the simulation of clinching processes. For this purpose, the correlation of interface pressure and the relative velocity between aluminum and steel sheet material in clinching processes is investigated using numerical simulation. Based on these findings, the developed concepts focus on determining friction coefficients at interface pressures of the above materials, yield stress, as well as the reproduction of the occurring friction conditions between sheet metal materials and tool surfaces in clinching processes using tool substitutes. Furthermore, wear investigations between sheet metal material and tool surface were carried out in the friction tests with subsequent EDX analyses of the frictioned tool surfaces. The developed method also allows an optical deformation measurement of the sheet metal material specimen by means of digital image correlation (DIC). Based on a methodological approach, the test setups and the test systems used are explained, and the functionality of the concepts is proven by experimental tests using different sheet metal materials.
\end{abstract}

Keywords Tribology $\cdot$ Sheet metal $\cdot$ Clinching $\cdot$ Simulation $\cdot$ Wear

\section{Introduction}

In the context of growing social environmental awareness, the automotive industry is forced to reduce the greenhouse gas emissions. To achieve emission-oriented goals, lightweight design proved to be a suitable approach. The resulting multi material mix requires innovative joining methods, since the established welding methods have reached their limits. This includes clinching, which allows assembling of two or more

Max Böhnke

max.boehnke@1wf.uni-paderborn.de

$1 \quad$ Laboratory for Material and Joining Technology, University of Paderborn, Pohlweg 47-49, 33098 Paderborn, Germany sheet metal parts by solely cold forming the material [1]. In the numerical simulation of clinching processes, the predictive accuracy depends on the friction model used and the implemented friction coefficients [2]. The frictional behavior between the joining partners is usually assumed based on literature values or determined by inverse parameter identification. However, this contradicts the predictive character of the numerical simulation. In order to guarantee a predictive quality of the joining process simulation, a precise friction model based on experimental data, needs to be implemented. Therefore, different methods aimed at the determining of friction coefficients have been developed. A frequently used test to determine the frictional behavior of materials for bulk metal forming is the ring compression test, which has already been adapted for mechanical joining in [3]. Therein, a concept for 
the adaption of the ring compression test to the specific needs of a shear-clinching process was presented. However, the process conditions here cannot be considered decoupled, so that the frictional parameters must be determined inversely. Due to this, the ring compression test is less suitable for deriving a proper friction model for mechanical joining processes. For sheet metal forming, the pin-on-disk test and strip drawing test are well known [4]. Nevertheless, these tests are not suitable for interface pressures above the materials yield stress.

Another tribological experiment is the tribo-torsion test, which consists of an axial load superimposed with a rotational torque. Therefore, a setup is needed which enables the application of an axial and torsional load to the specimen simultaneously. This test setup is successfully applied for hot [5] and cold [6] extrusion processes. Therein, various experimental setups have been developed in which the frictional behavior of metallic materials could be investigated under variation of contact pressure, temperature, and relative velocity. However, only the friction conditions between tool and workpiece in bulk metal-forming processes were investigated. Friction tests with sheet metal materials by means of the tribo-torsion test are not known. The tribo-torsion test enables a decoupled consideration of the influencing parameters. High temperature tests can be carried out via an inductive coil [5]. In [7] contact stresses of up to eight times, the initial flow stress of soft aluminum and relative speeds of $47 \mathrm{~mm} / \mathrm{s}$ could be tested. In this range of parameters are also the local process parameters which occur during clinching.

Based on the tribo-torsion test, a new method for the experimental determining of friction coefficients between sheet metal materials under consideration of the specific process conditions of clinching processes is developed and functionally demonstrated in [8]. Therein, the frictional behavior of the sheet material EN AW-6014 T4 is investigated under variation of the interface pressure as well as the relative velocity. The method consists of a mirror symmetrical test setup in which circular sheet metal specimen is fixed in force- and formfitting mountings and rotated against each other. The method is suitable for determining the frictional behavior between sheet metal materials. However, the method is limited in terms of achievable contact stresses as the maximum applicable interface pressure has to be slightly above the yield stress of the investigated material. Furthermore, no other contact situations, for example, the friction between clinching tool like punch and die and sheet metal are investigable.

In order to be able to comprehensively understand the occurring frictional behavior during the clinching process, it is necessary to investigate the contact between the tool and the sheet metal. Numerical analyses of clinching processes demonstrated that the frictional behavior between the clinching tools, such as punch and die, and joining parts, plays an important role. The friction occurring during the clinching process impacts the material flow and thus the geometrical formation of the clinched joint, especially the interlock, which in turn directly influences the load-bearing capacity of a clinched joint $[9,10]$. These publications extensively focus on the numerical analysis of the clinching process and the factors influencing the geometric formation of the joining point. The variation of the friction conditions in the validated simulation models of the clinching processes showed a clear influence on the formation of the interlock in the clinched joint. In [11], the strain intensity distribution of the material in a clinched joint was investigated by means of numerical simulation. The highest values are observed near the necking area as well as in the connection axis near the interior sheet line. This is a result of high friction between the surface of the punch contact and the sheet metal material, which significantly affects material deformation and flow. Another aspect to be investigated when studying frictional behavior during clinching processes is high interface pressures that occur during the formation of the joint. They can locally exceed the yield stress of the material considerably, which can lead to completely new material behavior with regard to friction. For example, the interface pressures in flat-clinching processes can reach up to $2500 \mathrm{MPa}$ [12]. Kaščák et al. [13] investigated clinching processes with rigid die in dual-phase steels using FE simulations. During the formation of the interlock, interface pressures of up to $2400 \mathrm{MPa}$ are present between punch and sheet metal material.

Another point to consider, which results from the relative displacements between the sheet metal material and the tools as well as the high interface pressures that occur, is tool wear. The increased usage of high-strength steels in the course of lightweight automotive construction accelerates tool wear [14]. While wear in forming technology influences component tolerances, wear reduces joint quality in joining technology. To be able to plan the maintenance intervals, it is necessary to know when the tools are worn and the joint quality is no longer acceptable [14].

In addition to empirical and material science models, wear is described analytically via models based on contact mechanics. The Archard model [15] is the major contact mechanics wear model. Like described in [14], is necessary to determine the wear coefficient experimentally. For mechanical joining processes, no standardized testing method is known to investigate the wear behavior of the tools. For parameterization of wear models, it is recommended that the process parameters of the wear test match those of the joining process. This leads to the conclusion that a new test setup is needed for investigating wear mechanisms in mechanical joining processes. Studies on tool wear have also been carried out in the field of mechanical joining technology. Meschut and Matzke [16] examined the wear for clinching TWIP steels. After 13,000 clinching points, a decrease of $0.05 \mathrm{~mm}$ in the interlock was detected, which emphasizes the impact of wear in mechanical joining processes. 
Taking into account the abovementioned aspects, this paper aims to develop concepts based on the tribo-torsion test method in order to investigate the frictional behavior between sheet metal parts as well as between sheet metal and clinching tools for the numerical modeling of clinching processes. Furthermore, the application of high interface pressures above the materials yield stress should be possible. In addition, investigations on wear mechanisms concerning the clinching tools surface will be conducted. In order to investigate the local material behavior during the tests, they are additionally recorded with installed optical measurement systems and evaluated by means of DIC software. Depending on the focus of the investigations, the concepts are installed in two different testing systems. To prove a versatile functionality, the concepts are tested with different aluminum and high-strength steel sheet materials, i.e., HCT590X, HX340LAD, EN AW-6014 T4, and EN AW-5182. In addition, the clinching tool material is investigated for its frictional behavior.

\section{Numerical simulation}

A simulation model was used to assess the friction-related parameters during the clinching process. The numerical model was created using the LS-DYNA simulation software. To reproduce the deformation behavior of the joining parts, the sheet metal material was modeled as elastoplastic, whereas the tools were modeled as elastic. The forming process is induced by a displacement of the punch. As both joining parts undergo considerable deformation during the joining process, a remeshing algorithm was used for both sheets. A Coulomb friction model is used, which has been configured with friction values described on the relevant technical or scientific literature. A friction coefficient of $\boldsymbol{\mu}=0.2$ was assumed for modeling the friction between the two sheet metal parts. The model pt? >is used to gain a general evaluation of the occurring friction relevant process parameters. The occurring relative velocities and the corresponding interface pressures, which change during the clinching process, are calculated using the simulation model and can be evaluated at different points. Therefore, the displacement of selected mesh nodes of the contacting joining parts is considered as well as single-surface segments in the contact area for calculating the interface pressure between them.

Fig. 1 shows the simulated results of a clinched joint, consisting of two parts out of a punch-sided steel sheet HCT590X, $t=1.5 \mathrm{~mm}$ and a die-sided aluminum alloy EN $\mathrm{AW}-6014$ in temper T4, $t=2.0 \mathrm{~mm}$. To consider the frictional behavior of the entire joint, discrete measuring points, illustrated by different colored dots, between the sheet metal parts were identified, which can be seen in the upper right corner. The selected points consider three contact scenarios, i.e., punch-sheet (red), sheet-sheet (yellow), and die-sheet (blue).
They range from the center of the clinching point at the bottom to the upper draw-in point. For each area, the interface pressure and corresponding relative velocity have been detected for several calculation steps during the process simulation.

The correlation is shown in the diagram of Fig. 1. It can be seen that different correlations between relative velocity and interface pressure may occur in the course of the clinching process, depending on the contact surface (see left side of Fig. 1). For sheet-sheet contacts, only low relative velocities predominate at interface pressures of up to $2500 \mathrm{MPa}$. In certain cases, the relative velocities increase to $1.0 \mathrm{~mm} / \mathrm{s}$ at interface pressures of around $700 \mathrm{MPa}$. Moderate velocities may occur between punch and sheet metal, with local interface pressures of up to $2500 \mathrm{MPa}$. The interface pressures between die and sheet are comparatively the lowest. A maximum pressure of up to $1500 \mathrm{MPa}$ was achieved. However, the relative velocities can reach a level of up to $3.0 \mathrm{~mm} / \mathrm{s}$ during the clinching process.

\section{Concept development}

The numerical analysis of the clinching process has demonstrated that during the formation of the clinched joint, in all contact situations, local interface pressures occur that significantly exceed the yield stress of the materials to be joined. In order to be able to simulate these process conditions and investigate the frictional behavior, appropriate concepts are required that allow friction tests at high interface pressures as well as the investigation of the friction conditions between tools and sheets.

\subsection{Concept for high interface pressures}

In order to reproduce high interface pressures in friction testing, it is necessary to prevent plastic flow of the friction specimens. Therefore, an encapsulation, such as that shown in [6], is used. In contrast to this concept, the encapsulation was constructed in two parts, due to the fact that a one-piece encapsulation leads to an additional, radially circumferential friction surface which distorts the results. Previously conducted tests have shown that a one-piece encapsulation causes a $69 \%$ higher frictional torque. Fig. 2 shows a defined gap between the end faces of the two-part enclosure. This gap is created before the start of the test by inserting thin sheet metal bodies which have to be removed before the start of the test. In doing so, the two components of the enclosure do not have any contact during the friction test. If friction tests were performed under high contact normal stresses without enclosure, the contact area would change. In addition, radial cracks in the specimen and thus material failure can be observed at very high (up to four times the initial yield stress for aluminum) 
Fig. 1 Correlation between the simulated interface pressures and the relative velocities generated in numerical simulation
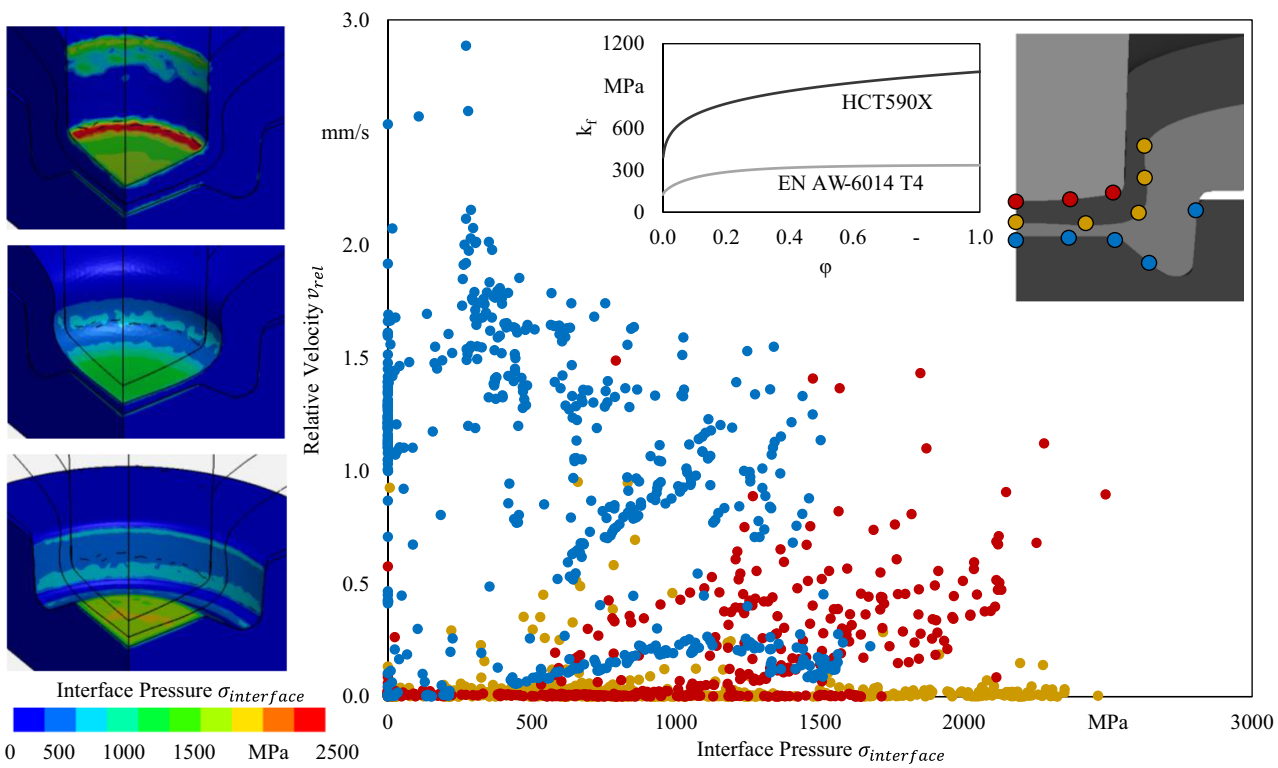

contact normal stresses. A defined friction test is no longer feasible.

\subsection{Concept for investigation of friction between tool and sheet metal}

In order to reproduce the frictional contact between clinching tools and sheet metal, special tool substitutes were developed, which can be integrated into the testing setup. The geometry of a tool substitute is shown in Fig. 3. The friction-relevant surface is highlighted separately in light blue. The inner and outer diameters of this circular ring surface correspond to the dimensions of a sheet metal specimen. This has the advantage of a standardized specimen shape and thus eliminates geometry effects in friction testing. In addition, friction tests under high interface pressures are possible as well. One half of the two-part encapsulation is used for this purpose. To ensure a valid mapping of the tool contact, it is necessary that the surface of the tool substitute corresponds to the surface of the joining tool. To this end, the surface roughness is compared before friction test. In addition, the tool substitute manufacturing methods should be similar to those applied for the joining tool. This concerns the manufacturing, coating, heating, and post-treatment processes of the tool substitutes. Fig. 3 also shows the fabricated tool substitute for a TOX A50100 punch from the same manufacturer of the clinching tools used (TOX Pressotechnik $\mathrm{GmbH}$ ). The diagram shows Abbott-Firestone curves, which are used to describe surface textures. The curves were created for a new punch and for a tool substitute produced using the same manufacturing process. Due to the similarity of the curves as well as the similarity of the values for $\mathrm{Ra}$, it is reasonable to assume that the surface conditions of the tool substitutes and clinching tools are comparable and that the friction behavior of the clinching tools with the corresponding substitute is feasible.

Fig. 4 shows the tool substitute in the test setup. The tool substitute sits in a special specimen mounting, which is flanged to the friction test rig. The tool substitute is pressed in the specimen mounting and fixed by a force-fit. The test scenario is identical to that of an entirely sheet-metal friction
Fig. 2 Concept for an encapsulated friction test setup for sheet metal specimen in order to prevent material flow

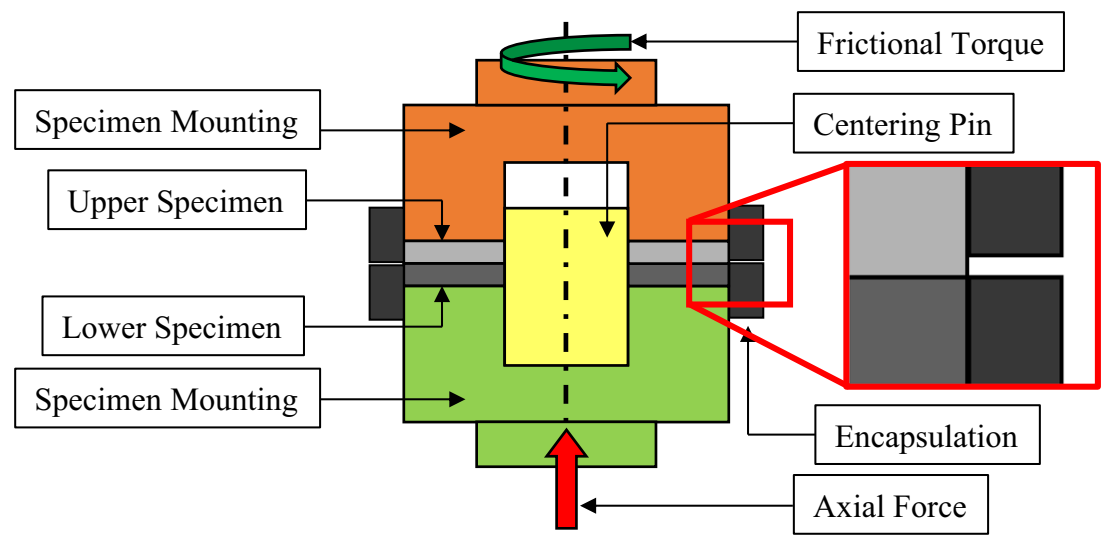


Fig. 3 Tool substitute and comparison of the surface conditions to clinching tools
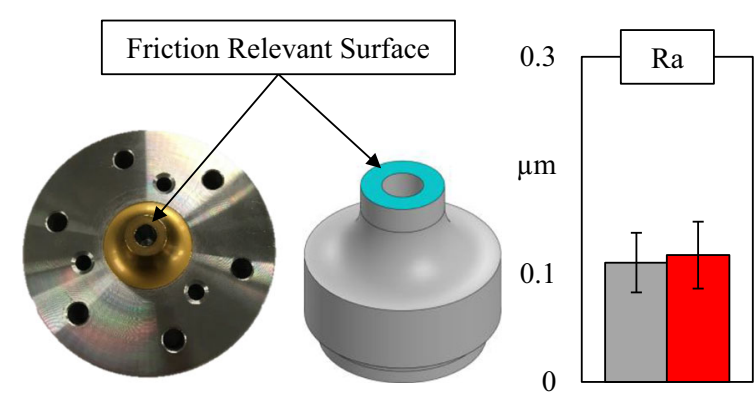

test. For high interface pressures, an encapsulation can also be added.

\section{Experimental}

\subsection{Investigated materials}

In order to verify the applicability of the developed concepts to materials with different properties, two different steel materials were investigated. These included a high-strength dual-phase steel HCT590X and a higher-strength micro-alloyed steel HX340LAD. In addition, investigations were carried out on two different aluminum alloys: a heat treatable AlMgSi-alloy EN AW-6014 in temper T4 and a naturally hard AlMg-alloy EN AW-5182 in temper O. The chemical compositions and mechanical properties of the investigated materials are documented in Table 1.

\subsection{Testing systems}

Different peripheral systems were used for the friction tests, in which the developed concepts are implemented, depending on the focus of investigation. On the one hand, the Axial-Torsion Testing System from [8] was used, which consists of two hydraulic cylinders that can be moved independently of each other. This enables the application of a translational contact force superimposed with a rotation of the mounted specimen or tool substitute. During the experiment, the lower setup rotates around its own axis and generates a relative rotation between the specimens, which generates a frictional torque. The required torque is measured over the entire test duration by an integrated sensor. The testing system is characterized by a very precise system control unit and measured data recording. In addition, entire pressure-velocity profiles can be applied by programming special test sequences. The system also has output interfaces for the measured friction torque and axial force values in order to feed them synchronously into other measuring systems such as DIC. However, the system is limited in its maximum rotation, which is $\pm 50^{\circ}$. It is also extremely expensive to purchase and thus very rare. Fig. 5 shows the test setup with implemented mountings and specimen in the Axial-Torsion Testing System as well as technical data.

On the other hand, the presented methodology of friction testing can be employed with other peripherals besides the Axial-Torsion System. One option is to use a Screw Test Bed. The figure below shows a test setup on a screw test stand from Kistler Instrumente AG (formerly Schatz AG). The screw test bed is equipped with a three-channel measuring device. In addition to the incremental recording of the angle of rotation and the analog torque recording, the normal force is also measured. This is recorded via an additional force ring. The signal from the DMS-based force ring is recorded in the measuring device synchronously with the other process parameters.

However, the screw test bed is not capable of dealing with high axial forces (maximum $200 \mathrm{~N}$ ). Therefore, a two-column frame must be used, which absorbs the axial forces, as shown in Fig. 6. The normal force is applied by a hydraulic cylinder that moves against a movable crossbeam. A specimen mounting is installed on the movable crossbeam. This specimen
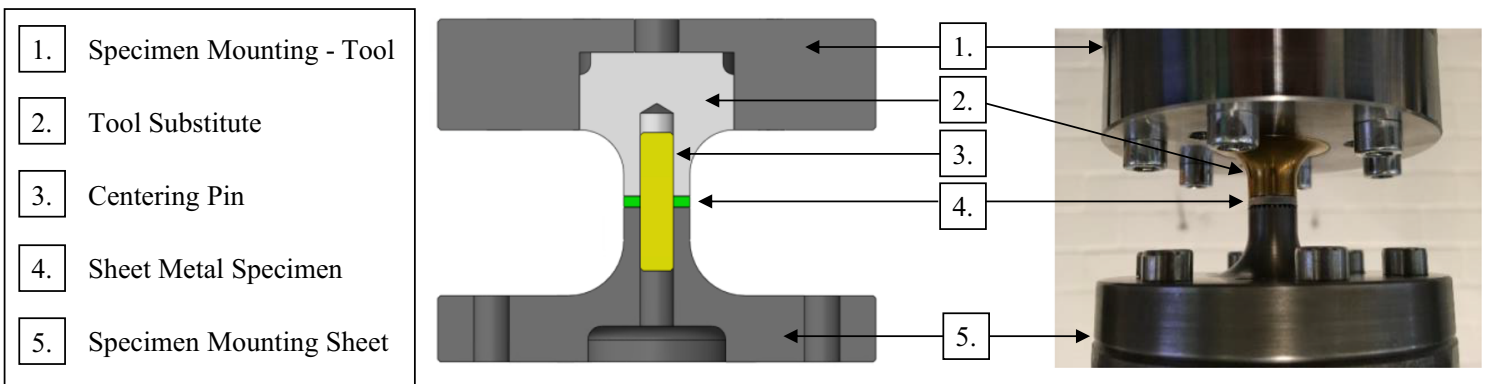

Fig. 4 Test setup for friction investigations using tool substitutes at low interface pressures 
Table 1 Chemical compositions and mechanical properties of investigated HCT590X [17], HX340LAD [18], EN AW-6014 T4 [19], and EN AW-5182 [20]

\begin{tabular}{|c|c|c|c|c|c|c|}
\hline \multirow{9}{*}{$\begin{array}{l}\text { Chemical comp. } \\
\text { (wt.-\%) }\end{array}$} & \multirow[b]{3}{*}{$\mathrm{C}$} & \multirow{3}{*}{$\begin{array}{l}\text { HCT590X } \\
\text { Max. } \\
0.15\end{array}$} & \multirow{2}{*}{$\begin{array}{l}\text { HX340LAD } \\
\text { Max. }\end{array}$} & & \multirow[t]{2}{*}{ EN AW-6014 T4 } & \multirow[t]{2}{*}{ EN AW-5182 } \\
\hline & & & & & & \\
\hline & & & 0.12 & $\mathrm{Si}$ & $0.3-0.6$ & 0.2 \\
\hline & $\mathrm{Si}$ & 0.75 & 0.5 & $\mathrm{Fe}$ & 0.35 & 0.35 \\
\hline & $\mathrm{Mn}$ & 2.5 & 1.4 & $\mathrm{Cu}$ & 0.25 & 0.15 \\
\hline & $\mathrm{P}$ & 0.04 & 0.03 & $\mathrm{Mn}$ & $0.05-0.20$ & $0.2-0.5$ \\
\hline & $\mathrm{S}$ & 0.015 & 0.025 & $\mathrm{Mg}$ & $0.4-0.8$ & $4.0-5.0$ \\
\hline & $\mathrm{Al}$ & 1.5 & Min. 0.015 & $\mathrm{Cr}$ & 0.2 & 0.1 \\
\hline & $\mathrm{Cr}+\mathrm{Mo}$ & 1.4 & - & $\mathrm{Zn}$ & 0.1 & 0.25 \\
\hline & $\mathrm{Nb}+\mathrm{Ti}$ & 0.15 & 0.25 & $\mathrm{Ti}$ & 0.1 & 0.1 \\
\hline & & & & $\mathrm{V}$ & 0.1 & - \\
\hline \multirow[t]{3}{*}{ Physical properties } & $R_{p 0,2}(\mathrm{MPa})$ & $330-430$ & $340-420$ & & $\leq 130$ & $\leq 130$ \\
\hline & $R_{m}(\mathrm{MPa})$ & $590-700$ & $410-510$ & & $\geq 175$ & $255-315$ \\
\hline & $A_{80}(\%)$ & $\geq 20$ & $\geq 21$ & & $\geq 23$ & $A_{50} \geq 12 \%$ \\
\hline
\end{tabular}

mounting moves with the crossbeam against the other specimen mounting that sits on a shaft with rotating bearings. A square is provided on the opposite face of the shaft, to establish the connection to the screw test stand. The two-column frame is designed for a maximum normal force of $100 \mathrm{kN}$. The maximum friction torque is $200 \mathrm{Nm}$. This can be applied at a maximum RPM of $5001 / \mathrm{min}$. This corresponds to a maximum relative velocity related to a mean specimen diameter of $4.5 \mathrm{~mm}$ of $235 \mathrm{~mm} / \mathrm{s}$. In contrast to the test setup with the Axial-Torsion Testing System, the bolt test rig is able to apply a quasi-unlimited torsion. Thus, it is possible to realize very large friction paths with the screw test bed. This offers the possibility of performing wear tests. The screw test bed can accommodate the same axial loads as the Axial-Torsion Testing System. The maximum axial force is limited by the two-column frame and the power of the hydraulic cylinder. This axial force can be extended by design measures. The kinematics of the test is possible only less complex compared to the Axial-Torsion Testing System. Due to its low investment costs, the screw test stand is ideally suited for use by small and medium-sized companies in application-related issues. Fig. 6 shows the setup and technical data of the screw test bed.

\subsection{Friction test procedure}

All tests are carried out at room temperature $\left(20^{\circ} \mathrm{C}\right)$. The tests are started with the application of the axial force on the specimens followed by the torsion of one of the specimens. To prevent the specimen mountings from deforming or failing during the tests they were made of a quenched and tempered tool steel with high compressive strength. For simulating a tool - sheet metal contact, one specimen mounting is replaced by a tool substitute for the friction test. For tests with interface pressures above the initial yield stress, a two-part encapsulation is used. During the tests, no tilting and no contact between the components of the encapsulation can be detected. Therefore, there is no additional friction surface. In exemplary

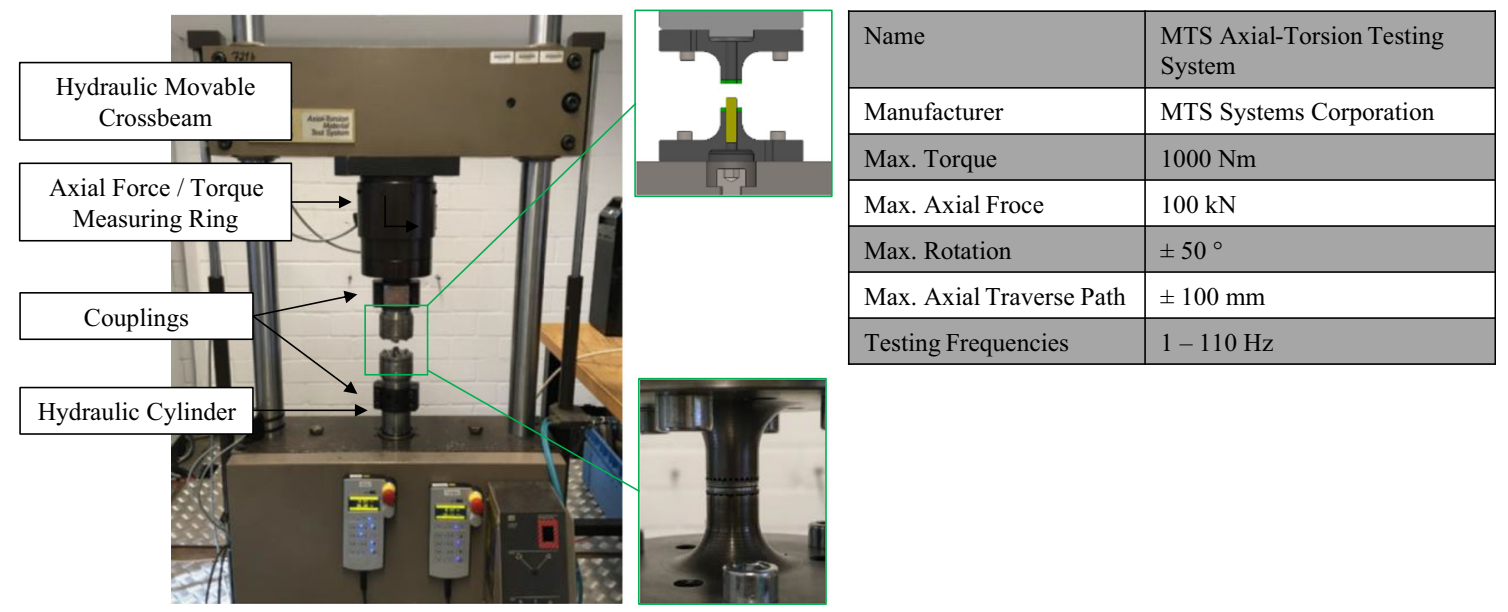

Fig. 5 Axial-Torsion Testing System for conducting friction tests with implemented sheet metal specimen mountings 


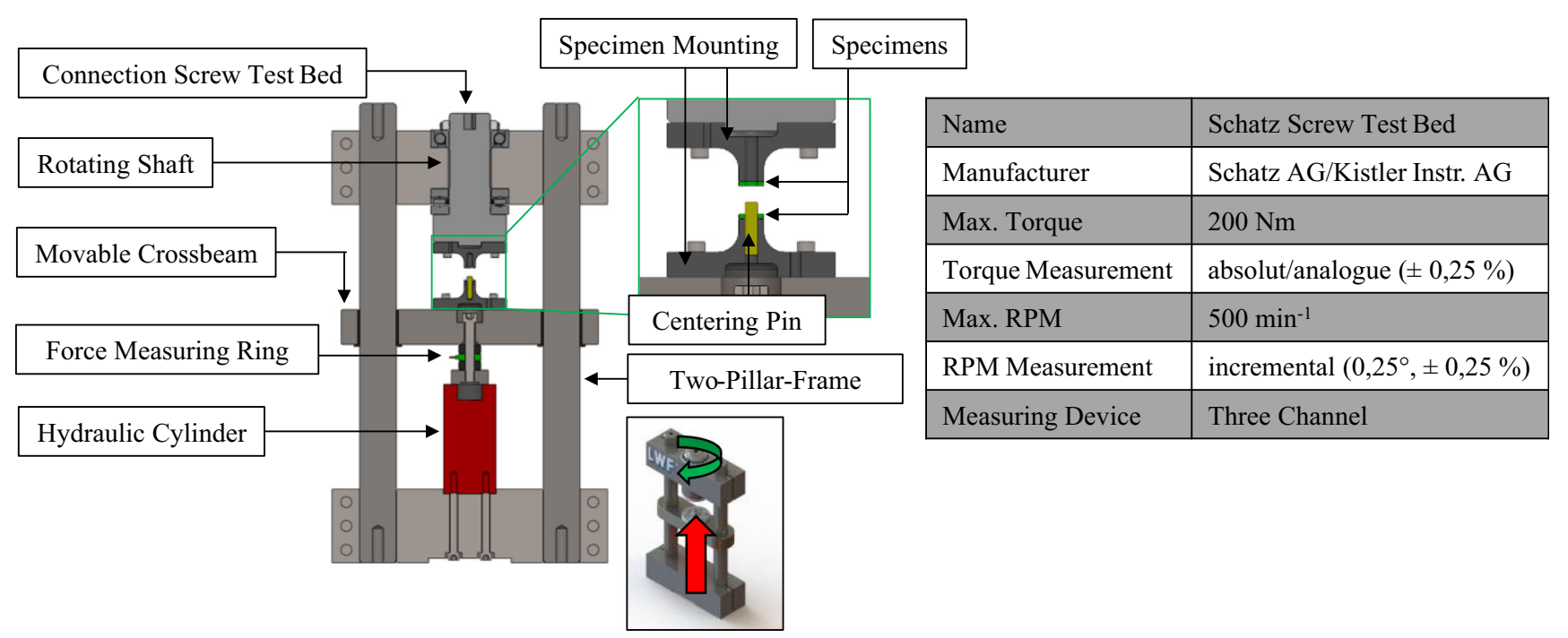

Fig. 6 Test setup and technical data of the screw test bed system for conducting friction tests

tests without encapsulation, radial cracks could be detected in the aluminum at high interface pressures (above $400 \mathrm{MPa}$ ). For this reason, plastic flow of the specimen materials must be prevented. At the start of the test, a sheet metal specimen was placed on the lower specimen mounting with one-half of the encapsulation placed over it. The encapsulation lies loosely on the radius of the specimen mounting. The encapsulation is flush with the sheet metal specimen. Spacers are then placed on top of the lower encapsulation on which the other half of the encapsulation with sheet metal specimen is placed. This ensures a defined gap between the enclosure components. The upper half of the encapsulation can therefore rotate without additional friction. After the normal force had been applied, the spacers were removed. The calculations of the actual interface pressure were done as described in [8], taking into account the true friction surface of the specimens after the friction test as well as the calculation of the friction coefficient.

\subsection{Local Measurement with DIC}

In order to measure the local displacement and deformation of the sheet metal specimen during the friction tests, the latter was conducted using a digital image correlation (DIC) system. This also enables to determine whether the relative displacement occurs entirely between the specimens or partially between the specimen and the mounting. For this purpose, the measured friction torque and axial force from the AxialTorsion-Testing System is transferred into the DIC system and synchronized with the recorded images. GOM ARAMIS 4M System was used for the tests, Fig. 7. Prior to testing, the mountings and specimen must be provided with a stochastic speckle pattern to ensure that the DIC system can detect facets and evaluate specimen deformation and displacement during the friction tests. The setup requires optical accessibility of the specimens, so that the deformation measurement can only be carried out in tests without encapsulation.

Fig. 7 shows a recorded image for a sheet-sheet contact friction test. To evaluate the deformation of the specimen such as local major strain $\varepsilon_{1}$, local compression strain $\varepsilon_{y}$ or shear angle $\vartheta_{\text {loc }}$ during the tests, surface components have to be created using the software. Based on this, a cylinder can be fitted to the lateral surface of a specimen. Local facet points (tracking points) on the specimens and mounting are rotated around the cylinder axis in order to compare the rotation angles of the specimen and the mounting.

\section{Results and discussion}

\subsection{High interface pressures}

For exemplary consideration of high interface pressures, the findings of the friction test of the EN AW-5182-HX340LAD contact are presented below. This is a pure-joining part contact. Interface pressures are considered which exceed the initial yield stress of EN AW-5182 by almost five times and the initial yield stress of HX340LAD by approx. 1.3 times. The tests are carried out with a relative velocity of $10 \mathrm{~mm} / \mathrm{s}$ and the friction stroke on the mean friction radius was $3 \mathrm{~mm}$ (Fig. 8).

With increasing interface pressure, it is noticeable that the specimens are more difficult to remove from the encapsulation after the friction test. Under the high interface pressures, the material flows radially against the encapsulation and the centering pin. Due to the higher ductility of EN AW-5182 compared to HX340LAD, it is more free-flowing and tends to be more difficult to remove.

The experiments at an interface pressure of approx. $67 \mathrm{MPa}$ (nominal: $50 \mathrm{MPa}$ ) generate a frictional shear stress of about $11 \mathrm{MPa}$. This corresponds to a friction coefficient of approx. $\mu$ 
Fig. 7 Test setup with local deformation measurement using DIC
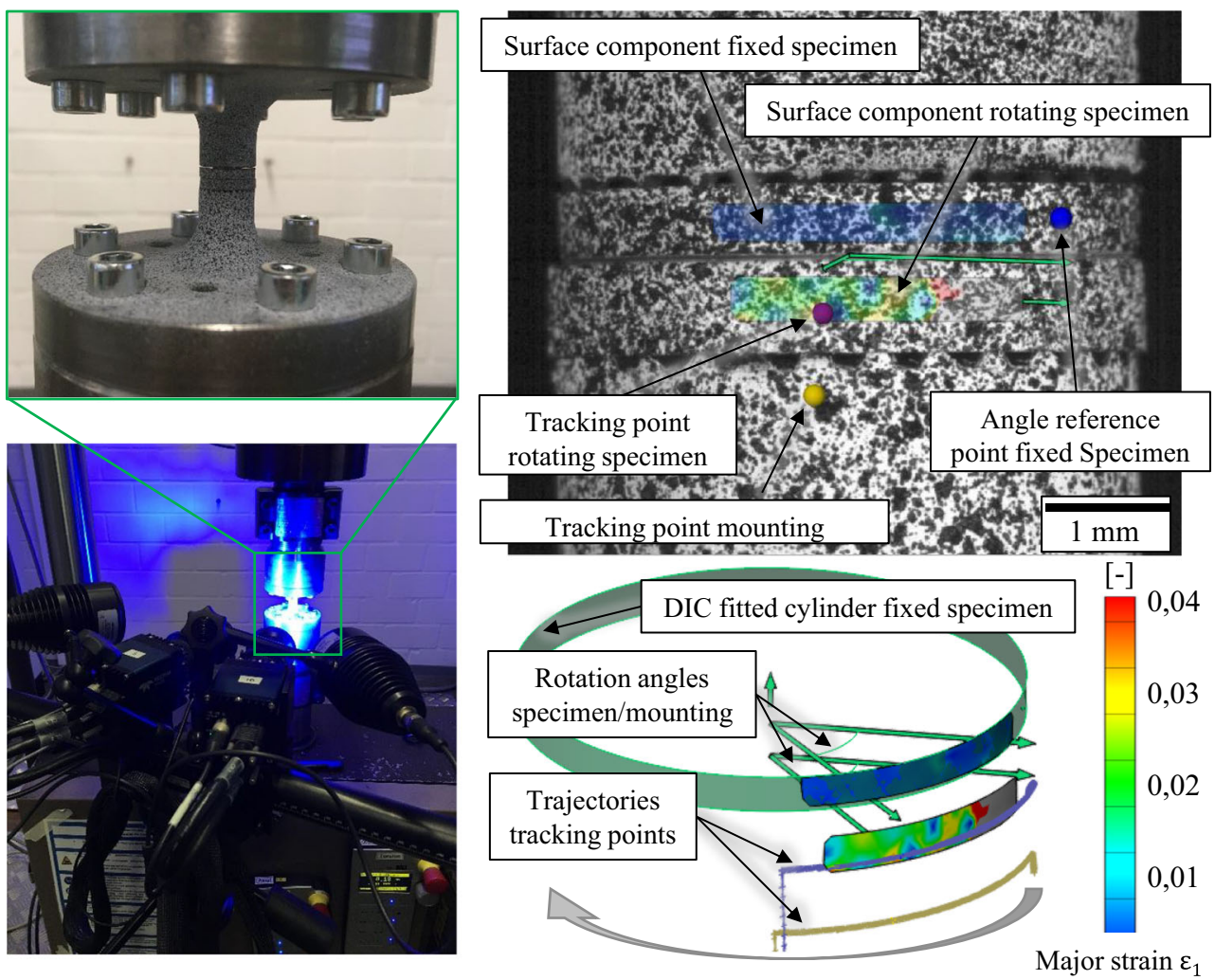

$=0.164$. With increasing interface pressure, the friction coefficient decreases. At an interface pressure of $408 \mathrm{MPa}$ (nominal: $300 \mathrm{MPa}$ ), the friction coefficient decreased to $\mu=0.136$. This results in a degressive, concave friction characteristic curve with increasing interface pressure. A further experiments carried out at nominal interface pressures of $588 \mathrm{MPa}$ (nominal: $500 \mathrm{MPa}$ ) produces a frictional shear stress at the level of about $75 \mathrm{MPa}$. This is equivalent to a friction coefficient of 0.1278 . The friction test at $664 \mathrm{MPa}$ (600 MPa nominal) interface pressure shows that the curve
Fig. 8 Test setup and results for friction tests with high interface pressures
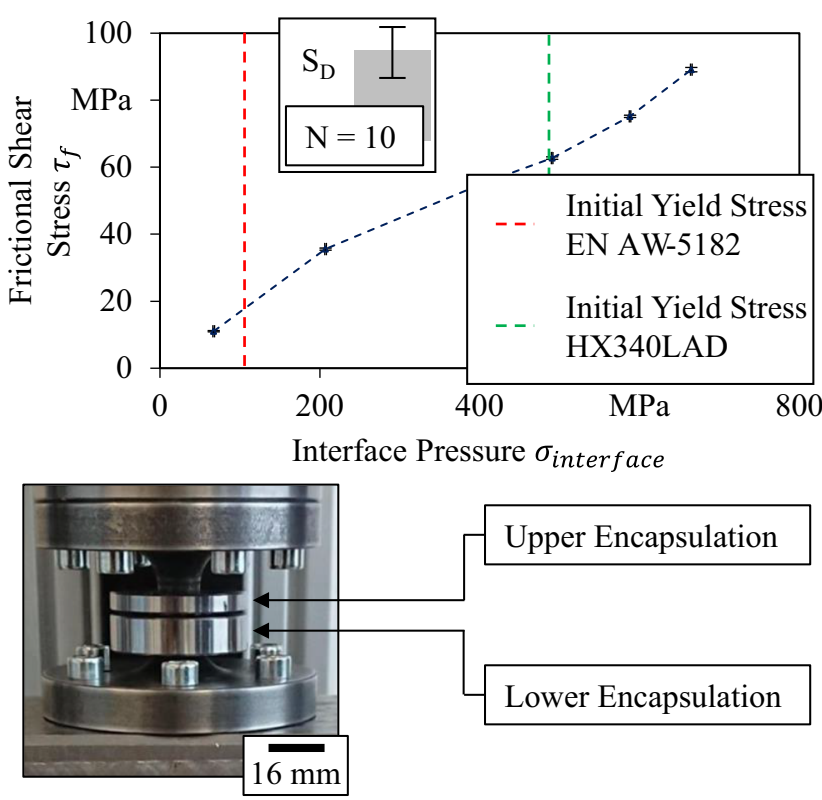

\begin{tabular}{|c|c|}
\hline Testing System \\
Screw Test Bed \\
\hline Friction Partner 1 \\
EN AW-5182; $\mathrm{t}=1.5 \mathrm{~mm}$ \\
\hline Friction Partner 2 \\
HX340LAD, $\mathrm{t}=1.5 \mathrm{~mm}$ \\
\hline Relative Velocity \\
\hline \multicolumn{1}{|c|}{$10 \mathrm{~mm} / \mathrm{s}$} \\
\hline Temperature \\
\hline Total Relative Displacement \\
\hline
\end{tabular}


of the frictional shear stress increases more sharply again. This may be due to an alloying effects and stronger plastic deformation of the specimens. Overall, the experimental results confirm that the concept of the encapsulation allows high interface pressures to be taken into account in the friction test.

\subsection{Tool substitutes}

An exemplary functional verification of friction tests with tool substitutes is shown in Fig. 9. The tests were conducted using a tool substitute with the surface conditions such as those for a clinching punch as well as specimen out of EN AW-6014 T4, $t$ $=2.0 \mathrm{~mm}$ and HCT590X, $t=1.5 \mathrm{~mm}$. The relative velocity chosen was $1.0 \mathrm{~mm} / \mathrm{s}$. The rotation angle was $80^{\circ}$, which corresponds to a friction slide of approx. $6.0 \mathrm{~mm}$. The tests were carried out at the nominal interface pressures of $100 \mathrm{MPa}$ and $300 \mathrm{MPa}$, respectively. The actual interface pressures, considering the actual friction surface between the specimens, were approx. 97 / $258 \mathrm{MPa}$ for EN AW-6014 T4 and 126 / $354 \mathrm{MPa}$ for HCT590X. The findings are shown in two different graphs in Fig. 9, consisting of the friction torque $M_{f}$ plotted over the rotation angle $\vartheta$ and the calculated friction coefficient $\mu$ plotted over the friction slide $s$ of the specimen. The graphs for the HCT590X specimen show the typical steep increase of the friction torque described by the peak at the beginning. Then, the transition to the kinetic friction can be detected by decreasing the friction moment followed by an approximately stationary state, ranging between $6.5 \mathrm{Nm}$ for the test carried out at $300 \mathrm{MPa}$ and 2.6 Nm for the test carried out at $100 \mathrm{MPa}$, respectively. The same curve progression can be seen for the calculated friction coefficient with a level of 0.073 for $300 \mathrm{MPa}$ and 0.093 for $100 \mathrm{MPa}$.

The graphs for the aluminum specimen however show a clearly different trend. The peak of the friction torque at the beginning of the test is followed by a subsequent significant increase that only slowly flattens in the further process of the test and turns into a stationary state, ranging between $31.2 \mathrm{Nm}$ at $300 \mathrm{MPa}$ and $14.1 \mathrm{Nm}$ at $100 \mathrm{MPa}$. This behavior could correspond to the changing surface conditions in the aluminum specimen (see chapter 5.3). The graph of the friction coefficient is similar and reaches a stationary level of 0.319 at $300 \mathrm{MPa}$ and 0.472 at $100 \mathrm{MPa}$.

\subsection{3 Wear testing}

A frictional wear test between a sheet metal joining part and a tool is shown in order to demonstrate the variable friction values with increasing friction stroke. The sheet metal material in this test is the natural hard aluminum alloy EN AW-5182 with a sheet thickness of $t=1.5 \mathrm{~mm}$. The tool substitute in the frictional wear test represents a clinching punch of the type AC56100 from TOX Pressotechnik $\mathrm{GmbH}$. The frictional wear test is performed at an interface pressure of $100 \mathrm{MPa}$ and a relative velocity of $1 \mathrm{~mm} / \mathrm{s}$ at room temperature $\left(20^{\circ} \mathrm{C}\right)$. The friction stroke in the test is approx. $0.3 \mathrm{~m}$. This corresponds to 10 revolutions or $3600^{\circ}$.

The results of the frictional wear test described in Fig. 10 demonstrate that the first experiment has a higher early local steady state than that detected in the second experiment. This is the area in which the dynamic friction coefficient is
Fig. 9 Results for friction tests using a tool substitute
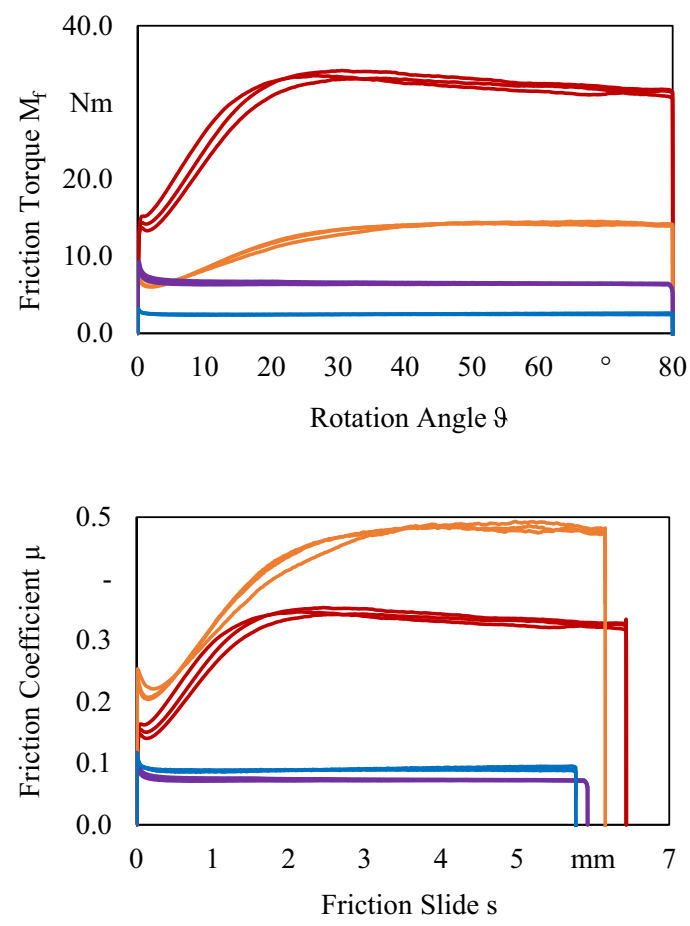
Fig. 10 Results for wear tests between sheet metal and tool substitute

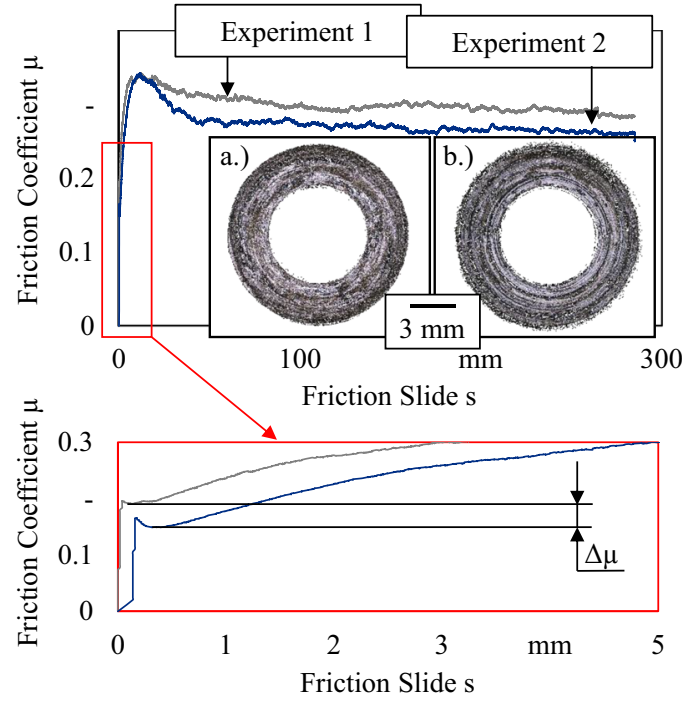

determined. While the first test has a dynamic friction coefficient of $\mu_{1}=0.19$, this is already reduced by more than $20 \%$ to $\mu_{2}=0.14$ in the second test. This can be seen in the lower graph. After overcoming the steady state, the friction coefficient increases to a maximum of $\mu=0.34$ in both experiments. Once this global maximum friction coefficient is reached, the friction coefficient decreases again in both experiments. While the curve of the first experiment drops almost linearly to $s=$ $100 \mathrm{~mm}$, the friction value of the second experiment drops exponentially. Both curves decrease to a level from which they only descend slowly in a linear manner. It is important to note here that the course of the first curve dwells at a higher level than the course of the second curve. This behavior is attributed to the progressive wear that takes place on the tool. As can be seen in the figure, aluminum material has been alloyed on the surface of the tool substitute, thus changing the friction conditions. The sheet metal specimens show clear grooves from the experimental test. This investigation shows the clear dependence of the friction conditions on the tools on the wear condition.

A more detailed investigation of the wear mechanisms was performed using EDX analysis, which can be seen in Fig. 11. The image on the left shows a SEM image of the friction surface of the tool substitute after the friction tests with clear adhesions in the form of material accumulations. The image in the middle shows the amount of iron on the surface as determined by EDX analysis, which is the main component of the tool substitute. In addition to iron, other elements have been detected which can be attributed to the coating of the substitute. The image on the right shows the detected amount of aluminum. It can be seen how aluminum particles have been alloyed over a large area on the substitute. This indicates that there is a considerable material adhesion during the friction tests, which affects the friction properties in the metal sheettool contact during the tests as well as in a clinching process.

\subsection{Optical measurement with DIC}

Fig. 12 shows the evaluated data generated by the DIC software. The upper diagram consists of two ordinates namely measured axial force $F_{a}$ and friction torque $M_{f}$ on the left side as well as the local major strain $\varepsilon_{1}$ of the specimens on the right side. For the shown diagram, a sheet-sheet contact was tested, using EN AW-6014 T4, $t=2.0 \mathrm{~mm}$ and HCT590X, $t=$ $1.5 \mathrm{~mm}$ and applying a nominal interface pressure of 300 $\mathrm{MPa}$. It can be seen how the major strain of the aluminum specimen increases while the axial force is set up for the friction test, since the tested interface pressure exceeds the yield
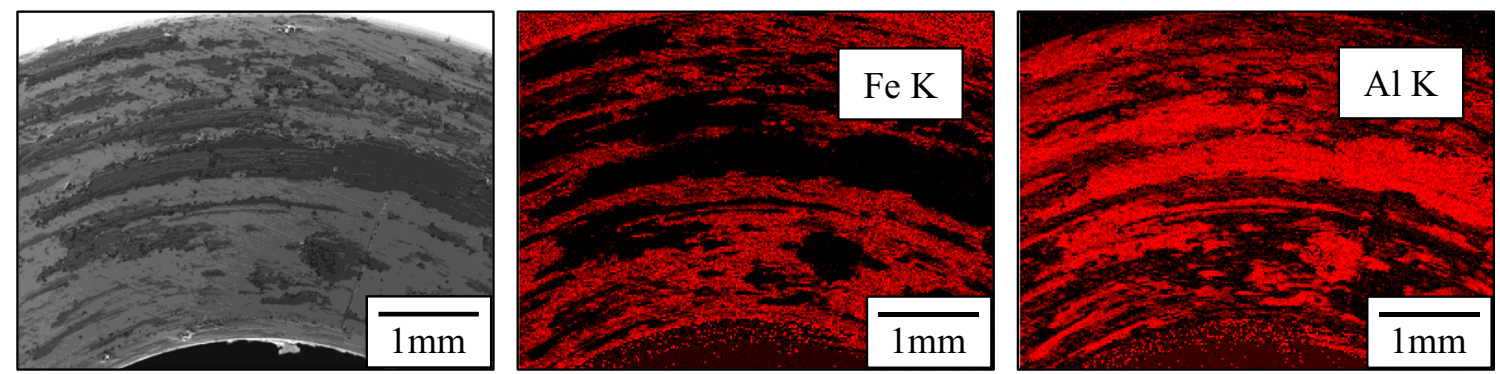

Fig. 11 EDX-surface-analysis of a tool substitute after friction tests 
Fig. 12 DIC measured deformation of the sheet metal specimen during friction tests
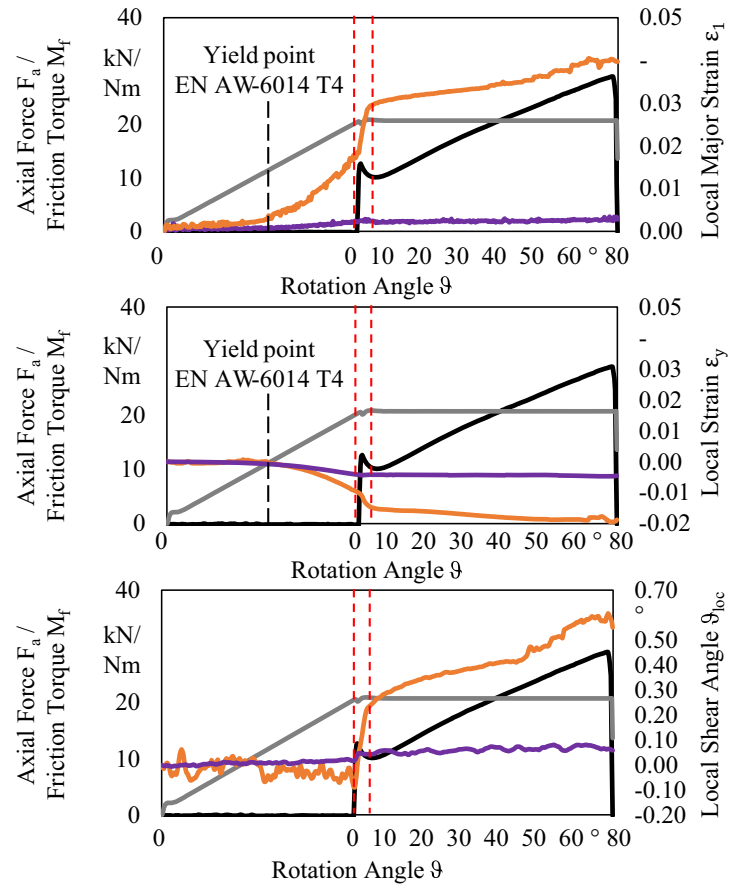

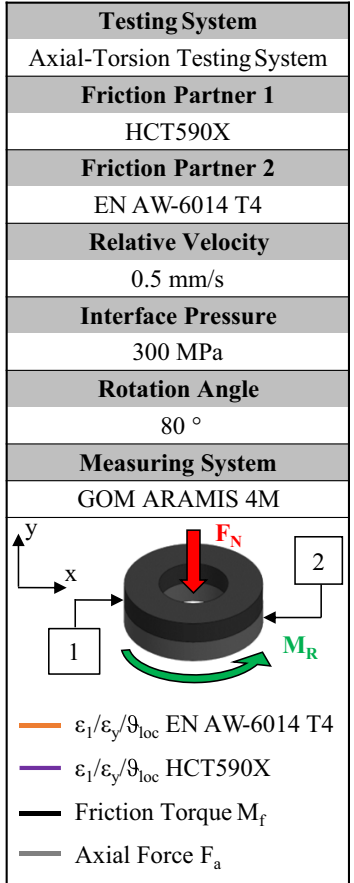

stress of EN AW-6014 T4. Whereas, no considerable increasing in major strain for the HCT590X specimen can be detected. With starting the friction test by rotating the specimen, the graph of the friction torque shows the initial static friction, described by the steep increase and the peak at the beginning. Afterwards, the transition to the kinetic friction can be recognized by decreasing the friction moment followed by another steady increase due to changing friction conditions during the test. The initial static friction goes along with a significant increase of the aluminum's major strain followed by a flattening but steadily rising graph up to 0.04 . The local strain $\varepsilon_{y}$, which refers to the specimens deformation in the compression direction during the friction test are shown in the middle graph. It can be seen that there is no significant deformation of the HCT590X specimen. Whereas, a considerable deformation of the EN AW-6014 T4 specimen occurs after exceeding the yield stress. The local strain $\varepsilon_{y}$ decreases, due to the compression of the specimen during the axial force is applied. When the specimen starts to rotate, the applied compressive stress is superimposed with the onset of shear stress. As a result, the material flow of the specimen is intensified, which leads to an increasing compression of the specimen that is continued throughout the test, as it can be seen from the steadily decreasing graph for $\varepsilon_{y}$ to approx. -0.02 .

The significant rise of the major strain in the aluminum specimens is based on its shearing during static friction with the starting rotation. The lower graph shows the local shear angle $\vartheta_{\text {loc }}$ which is related to the right ordinate. This also shows a significant increase in the aluminum specimen with the onset of friction, as well as the graph resembles that of the major strain in the further course going up to $0.6^{\circ}$ local shearing. Whereas, only slight deformations take place in the HCT590X specimen.

Concerning the relative displacement between mounting and specimen, the measurement of the rotation angles showed that the specimen only rotate $76.3^{\circ}$ and the mounting $76.7^{\circ}$. This shows that, except for a marginal percentage of $0.5 \%$, the entire relative displacement takes place between the sheet metal specimens. It also shows that there is a difference between the global angle measurement of the testing system and the locally measured rotation angle on the specimen. The difference is due to the torsional stiffness of the testing system as well as slip processes in the flanged mounting with starting rotation.

\section{Conclusion and outlook}

In conclusion, the further developed concepts for the tribo-torsion testing method show reproducible results for applying them in frictional investigations concerning sheet metal-tool contacts as well as for interface pressures above the yield strength of the investigated materials. With this new concepts, the frictional behavior of sheet metal materials can be investigated under previously unfeasible test conditions. Compared to previously used tests such as pin-on-disk tests, this concept allows higher pressures to be achieved as well as friction paths of any length in order to investigate wear behavior. Compared to the ring compression test, the presented concept has the advantage that the process parameters can be investigated decoupled from each other and no inverse parameter identification is necessary. 
In this study, a previous numerical simulation of the clinching process shows different interface pressures and relative velocities, depending on the contact situation. Therein, interface pressures up to $2500 \mathrm{MPa}$ were determined in combination with relative velocities that can reach a level of up to $3.0 \mathrm{~mm} / \mathrm{s}$. An encapsulation was developed and added to the mounting to prevent material flow during the tests and to enable investigations at high interface pressures. This enabled interface pressures of up to $664 \mathrm{MPa}$ to be achieved during the tests. For higher interface pressures, the mountings must be adapted and made of harder materials. Otherwise, they could deform and the specimens would slip during the tests. The same applies to ultra-high-strength materials. The concept is very well suited for investigations up to tensile strengths of $600-700 \mathrm{MPa}$, but would fail for press-hardened steels, due to deformations in the mountings. Furthermore, the specimen geometry could be varied to achieve higher interface pressures, as the used testing systems are limited in their axial force. In addition, a new concept based on the tool substitutes has been developed in order to investigate the sheet metal-tool contact during clinching processes. The production of such tool substitutes is very complex, but the only possibility to integrate them into the current concept. In the future, the concept could be further developed so that the tests can be carried out directly with tools such as dies or punches. The tests were carried out on a peripheral system, which allows wear investigations. During the wear tests, a significant dependency between friction path and friction properties was revealed. Due to the rotationally symmetrical design, the concept can be used to investigate friction paths of any length. It is therefore ideally suited for determining experimental values for wear models. Furthermore, the implementation in another testing system allows local deformation measurement of the specimens using DIC, when no encapsulation is necessary. Measuring with DIC has shown that, except for a marginal percentage of $0.5 \%$, the entire relative displacement takes place between the sheet metal specimens, which demonstrates the functionality of the mounting concept. To ensure a comprehensive process analysis regarding the friction behavior between the sheet metal parts in clinching processes, the method will be modified in order to map out an entire interface pressure-velocity-profile of specific areas in the clinched joint. Based on the data obtained in this way, a friction model for the process simulation will be developed.

Author contribution Max Böhnke and Moritz Rossel conducted the experiments, analyzed the data, and wrote the manuscript. Christian R. Bielak performed the numerical simulation. Mathias Bobbert discussed the data and contributed to refining the investigations. Gerson Meschut supervised the research and contributed to the final version of the manuscript. All authors read and approved the final manuscript.
Funding Open Access funding enabled and organized by Projekt DEAL. This research project is funded by the German Research Foundation (DFG, Deutsche Forschungsgemeinschaft)-TRR 285-Project-ID 418701707 as well as the German Federation of Industrial Research Associations (AiF) funded the IGF research project $20235 \mathrm{~N}$ by the European Research Association for Sheet Metal Working (EFB) under the program for promotion of industrial research (IGF) by the Federal Ministry for Economic Affairs and Energy (BMWi) based on a decision of the German Bundestag.

Data availability The data used or obtained in the current research can be obtained from the corresponding author upon reasonable request.

Code availability Not applicable.

\section{Declarations}

Conflict of interest The authors declare no competing interests.

Open Access This article is licensed under a Creative Commons Attribution 4.0 International License, which permits use, sharing, adaptation, distribution and reproduction in any medium or format, as long as you give appropriate credit to the original author(s) and the source, provide a link to the Creative Commons licence, and indicate if changes were made. The images or other third party material in this article are included in the article's Creative Commons licence, unless indicated otherwise in a credit line to the material. If material is not included in the article's Creative Commons licence and your intended use is not permitted by statutory regulation or exceeds the permitted use, you will need to obtain permission directly from the copyright holder. To view a copy of this licence, visit http://creativecommons.org/licenses/by/4.0/.

\section{References}

1. Kaščák L', Spišák E, Kubík R et al (2018) The evaluation ofpProperties of mechanically clinched joints made of ferrous and non-ferrous materials. Adv Sci Technol Res J 12:162-170. https:// doi.org/10.12913/22998624/85659

2. Schmid E, Hahn O (2004) Numerische Analyse des Clinchprozesses mit dreigeteilter Matrize. Zugl.: Paderborn, Univ., Diss., 2004 von Elisabeth Schmid. In: Berichte aus dem Laboratorium für Werkstoff- und Fügetechnik, vol 55. Shaker, Aachen

3. Müller M, Vierzigmann U, Hörhold R et al (2015) Development of a testing method for the identification of friction coefficients for numerical modeling of the shear-clinching process. KEM 639: 469-476. https://doi.org/10.4028/www.scientific.net/KEM.639. 469

4. Buchner B, Weber A, Buchmayr B (2008) Investigation of friction in warm forging of AA6082. Int J Mater Form 1:1215-1218. https://doi.org/10.1007/s12289-008-0160-7

5. Hora P, Gorji M, Berisha B (2011) Modeling of friction phenomena in extrusion processes by using a new torsion-friction test. KEM 491:129-135. https://doi.org/10.4028/www.scientific.net/KEM. 491.129

6. Teller M, Seuren S, Bambach M, Hirt G (2015) A new compression-torsion-tribometer with scalable contact pressure for characterization of tool wear during plastic deformation. Conf Papers in Science 2015:1-6. https://doi.org/10.1155/2015/496515

7. Teller M, Bambach M, Hirt G (2015) A compression-torsion-weartest achieving contact pressures of up to eight times the initial flow 
stress of soft aluminium. CIRP Ann 64:289-292. https://doi.org/10. 1016/j.cirp.2015.04.086

8. Rossel M, Böhnke M, Bielak C et al (2021) Development of a method for the identification of friction coefficients in sheet metal materials for the numerical simulation of clinching processes. KEM 883:81-88. https://doi.org/10.4028/www.scientific.net/KEM.883.81

9. Coppieters S (2012) Experimental and numerical study of clinched connections. (Doctoral thesis, Katholieke Universiteit Leuven Faculty of Engineering, Kasteelpark Arenberg 1, B-3001 Leuven, Belgium)

10. Jónás S, Tisza M (2020) Effect of the friction coefficient on clinch joints. IJEMS 5:86-90. https://doi.org/10.21791/IJEMS.2020.2.11

11. Mucha $J$ (2011) The analysis of lock forming mechanism in the clinching joint. Mater Des 32:4943-4954. https://doi.org/10.1016/ j.matdes.2011.05.045

12. Härtel S, Graf M, Gerstmann T, Awiszus B (2017) Heat generation during mechanical joining processes - by the example of flatclinching. Procedia Eng 184:251-265. https://doi.org/10.1016/j. proeng.2017.04.093

13. Kašč́k L, Spišák E, Kubik R, Mucha J (2016) FEM analysis of clinching tool load in a joint of dual-phase steels. Strength Mater 48:533-539. https://doi.org/10.1007/s11223-016-9795-7
14. Hoffmann H, Nürnberg G, Ersoy-Nürnberg K, Herrmann G (2007) A new approach to determine the wear coefficient for wear prediction of sheet metal forming tools. Prod Eng Res Dev 1:357-363. https://doi.org/10.1007/s11740-007-0065-1

15. Archard JF (1953) Contact and rubbing of flat surfaces. J Appl Phys 24:981-988. https://doi.org/10.1063/1.1721448

16. Meschut G, Matzke M (2016) Mechanisches Fügen hochmanganhaltiger TWIP-Stähle. EFB-Forschungsbericht, vol 431. Europäische Forschungsgesellschaft für Blechverarbeitung e.V. (EFB), Hannover

17. Salzgitter Flachstahl (2019) HCT590X - Material data sheet

18. DIN Deutsches Institut für Normung (2015) Continuously hot-dip coated steel flat products for cold forming - Technical delivery conditions

19. Novelis GLobal Automotive (2019) EN AW-6014 T4 - Material data sheet: Novelis Advanz 6F - e170

20. DIN Deutsches Institut für Normung (2019) Aluminium and aluminium alloys - chemical composition and form of wrought products: Part 3: Chemical composition and form of products

Publisher's note Springer Nature remains neutral with regard to jurisdictional claims in published maps and institutional affiliations. 